\title{
RECRYSTALLIZATION IN SINGLE CRYSTALS OF NICKEL BASE SUPERALLOYS
}

\author{
R. Bürgel *, P. D. Portella **, J. Preuhs *** \\ * Osnabrück University of Applied Sciences, \\ Albrechtstrasse 30, D-49076 Osnabrück, Germany \\ ** Federal Institute for Materials Research and Testing (BAM), \\ Unter den Eichen 87, D-12205 Berlin, Germany \\ *** DONCASTERS Precision Castings-Bochum GmbH (DPC), \\ Bessemerstrasse 80, D-44793 Bochum, Germany \\ e-mail addresses: r.buergel@fh-osnabrueck.de; pedro.portella@bam.de;.jpreuhs@doncasters.com
}

\begin{abstract}
The recrystallization behavior of some monocrystalline superalloys was investigated both in the temperature regime of solutioning as well as at lower temperatures in the $\gamma+\gamma^{\prime}$ field. At very high temperatures new grains already form after a small plastic deformation of about $1 \%$. They only nucleate at the surface in single-phase $\gamma$ areas if the degree of cold work is not too high. Grain boundary motion is stopped by interdendritic $\gamma / \gamma^{\prime}$ areas but is barely retarded by carbides and residual eutectic islands. Even very extended recovery annealing procedures are not able to prevent recrystallization during subsequent full solutioning. For the process of cellular recrystallization in the $\gamma+\gamma^{\prime}$ field higher degrees of cold work are necessary. In this case a $\gamma^{\prime}$ free zone must be absent to initiate new grains. Along the moving grain boundary the $\gamma^{\prime}$ phase is taken into solution and reprecipitated immediately behind it. A thin recrystallized surface "jacket" leads to a higher crack density under LCF conditions but for the chosen parameters in this work the number of cycles to crack initiation is not affected.
\end{abstract}

\section{$\underline{\text { Introduction }}$}

Recrystallization poses one of the major difficulties in post casting processing of directionally solidified, especially single crystal blades of nickel base superalloys. There are several possible sources for the necessary plastic deformation during manufacturing and processing of the new parts as well as during service and reconditioning: contraction stresses during cooling of the solid in the shell mold, removing the ceramic mold and core material mechanically, stamping identification marks, grinding the airfoil and the fir tree root to net shape, impact damage, removing of coating residues mechanically, etc. The deformation is either concentrated at the component surface or can extend into the bulk material. Figure 1 shows an example of unacceptable recrystallization in the root-airfoil transition area after solution heat treatment of a new part.

The formation of new grains can take place during solutioning heat treatment even after relatively small degrees of work. Higher amounts of plastic deformation are needed to initiate recrystallization at lower temperatures, e.g. during age hardening or service exposure.

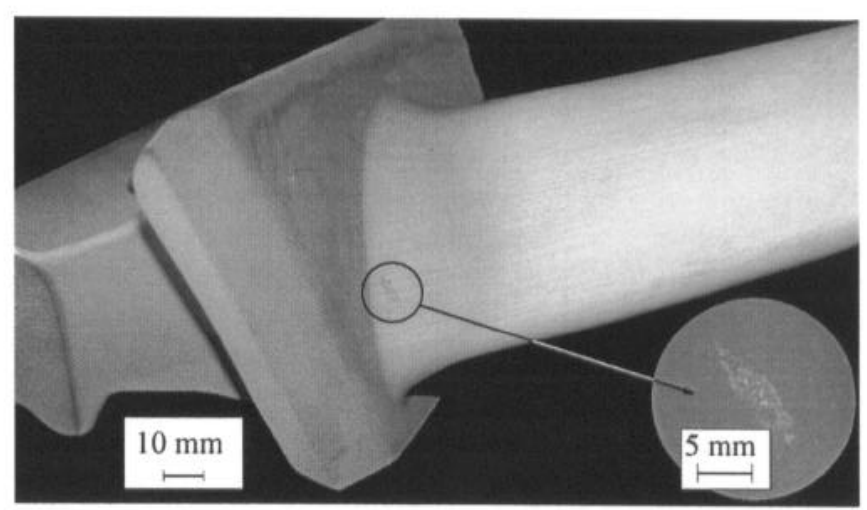

Figure 1: Recrystallization phenomena on a turbine airfoil after solution heat treatment. 
Recrystallization may dramatically reduce the fatigue life and also the stress rupture strength of directionally solidified components. Therefore, specifications typically limit recrystallized grains to a diameter of about $1 \mathrm{~mm}$ in the airfoil, with additional restrictions concerning maximum number of new grains and the distance between recrystallized areas.

Little information is available in the open literature on recrystallization of monocrystalline and columnar-grained components and possible methods of preventing it. Mostly surface deformation was stimulated, e.g. by hardness indentations or shot peening, and consequently recrystallization was initiated at the surface only ${ }^{[1-4]}$. The main purpose of the present investigation was to find out the mechanisms responsible for the formation and growth of new grains and whether recrystallization could be reduced or even suppressed. The work comprises two distinct parts: the first deals with recrystallization phenomena during solution heat treatment, i.e. in the $\gamma$ region, and the second with recrystallization during annealing or service exposure in the $\gamma+\gamma^{\prime}$ field.

The alloys investigated were developed as blading material both for industrial gas turbines (CMSX-11B, PWA 1483) as well as for aircraft propulsion (SRR 99, CMSX-6).

\section{Experimental}

\section{Alloys investigated}

Table I shows the nominal chemical compositions of the alloys investigated. Recrystallization studies in the $\gamma$ region were focused on CMSX-11B in comparison to PWA 1483 and SRR 99. For the behavior in the $\gamma+\gamma^{\prime}$ field CMSX -6 was chosen.

Table I Nominal chemical compositions in w\% of the alloys investigated (balance: $\mathrm{Ni}$ )

\begin{tabular}{l|c|c|c|c|c|c|c|c|c|c} 
& $\mathrm{Cr}$ & $\mathrm{Co}$ & $\mathrm{Mo}$ & $\mathrm{W}$ & $\mathrm{Ta}$ & $\mathrm{Nb}$ & $\mathrm{Al}$ & $\mathrm{Ti}$ & $\mathrm{C}$ & $\mathrm{Hf}$ \\
\hline CMSX-11B & 12.5 & 7 & .5 & 5 & 5 & .1 & 3.6 & 4.2 & - & .04 \\
\hline PWA 1483 & 12.2 & 9 & 1.9 & 3.8 & 5 & - & 3.6 & 4.1 & .07 & - \\
\hline SRR 99 & 8.5 & 5 & - & 9.5 & 2.8 & - & 5.5 & 2.2 & .02 & - \\
\hline CMSX-6 & 10 & 5 & 3 & - & 2 & - & 4.8 & 4.7 & - & .08
\end{tabular}

Cylindrical bars were cast in Bridgman furnaces with their longitudinal axes in the [001] direction with not more than $10^{\circ}$ deviation.

The heat treatments of the alloys are given in Table II.

\section{Heat treatments}

The heat treatments for investigation of the solutioning and recrystallization behavior in the $\gamma$ field were performed under air atmosphere in a laboratory furnace which was accurately controlled by two calibrated thermocouples of type B and S. For comparison purposes some tests were run in a vacuum production furnace. In any case when a certain annealing treatment is mentioned in the text below, the steps of the solution heat treatment cycle according to the values given in Table II were run additionally up to the respective annealing temperature. The experiments in the $\gamma+\gamma^{\prime}$ field were performed under an argon/ hydrogen atmosphere.
Table II Heat treatments of the alloys investigated

\begin{tabular}{l|l|l}
\multirow{2}{*}{ CMSX-11B } & $\begin{array}{l}\text { solutioning, } \\
\text { SHT* }\end{array}$ & $\begin{array}{l}1204^{\circ} \mathrm{C} / 2 \mathrm{~h}+1227^{\circ} \mathrm{C} / 2 \mathrm{~h}+1249^{\circ} \mathrm{C} / 3 \mathrm{~h} \\
+1260^{\circ} \mathrm{C} / 6 \mathrm{~h} ; \text { heating with } 1 \mathrm{~K} / \mathrm{min}\end{array}$ \\
\cline { 2 - 3 } & age hdn. & $1120^{\circ} \mathrm{C} / 5 \mathrm{~h}+870^{\circ} \mathrm{C} / 24 \mathrm{~h}+760^{\circ} \mathrm{C} / 30 \mathrm{~h}$ \\
\hline \multirow{2}{*}{ PWA 1483 } & solutioning* & $1260^{\circ} \mathrm{C} / 1 \mathrm{~h}$ \\
\cline { 2 - 3 } SRR 99 & age hdn. & $1090^{\circ} \mathrm{C} / 4 \mathrm{~h}$ \\
\hline \multirow{4}{*}{ solutioning* } & $\begin{array}{l}1270^{\circ} \mathrm{C} / 0,5 \mathrm{~h}+1280^{\circ} \mathrm{C} / 1 \mathrm{~h}+1290^{\circ} \mathrm{C} / 2 \mathrm{~h} \\
+1300^{\circ} \mathrm{C} / 0,5 \mathrm{~h}+1305^{\circ} \mathrm{C} / 0,5 \mathrm{~h} ; \\
\text { heating with } 1 \mathrm{~K} / \mathrm{min}\end{array}$ \\
\hline \multirow{2}{*}{ CMSX-6 } & age hdn. & $1080^{\circ} \mathrm{C} / 4 \mathrm{~h}+870^{\circ} \mathrm{C} / 16 \mathrm{~h}$ \\
\hline & solutioning* & $\begin{array}{l}1227^{\circ} \mathrm{C} / 2 \mathrm{~h}+1238^{\circ} \mathrm{C} / 2 \mathrm{~h}+1271^{\circ} \mathrm{C} / 2 \mathrm{~h} \\
+1277^{\circ} \mathrm{C} / 3 \mathrm{~h}+1280^{\circ} \mathrm{C} / 2 \mathrm{~h} ; \text { heating } \\
\text { with } 1 \mathrm{~K} / \mathrm{min}\end{array}$ \\
\hline & & $1080^{\circ} \mathrm{C} / 4 \mathrm{~h}+870^{\circ} \mathrm{C} / 16 \mathrm{~h}$ \\
\hline
\end{tabular}

* SHT: Solution heat treatment. Additional steps at lower temperatures may precede the solutioning to equilibrate the furnace.

Samples for $\gamma^{\prime}$ solutioning behavior

To quantify the amount of $\gamma^{\prime}$ precipitates as a function of temperature for CMSX-11B as-cast specimens were heated to temperature, held for $2 \mathrm{~h}$, and then quenched in water to freeze the microstructure which had developed at the annealing temperature. This procedure was repeated in temperature intervals of $10 \mathrm{~K}$ up to the highest step of the solutioning heat treatment (see Table II).

The remaining volume fraction of the $\gamma^{\prime}$ phase, excluding eutectic $\gamma^{\prime}$, was determined through the area fraction in SEM micrographs of longitudinal sections.

Samples for recrystallization in the $\gamma$ field

Samples of $12 \mathrm{~mm}$ diameter and $18 \mathrm{~mm}$ height were sectioned deformation-free and exactly parallel-sided by wire-guided electro discharge machining (EDM). Deformation of test pieces in the as-cast condition was applied by axial compression at room temperature, the degrees of cold work being given as relative height reduction.

Some samples of CMSX-11B were coated after cold work by a standard CVD aluminizing process used for airfoil coating in the aero turbine industry. The maximum temperature of the coating cycle was $1080^{\circ} \mathrm{C}$ and a layer of about $60 \mu \mathrm{m}$ thickness was produced.

For metallographic analysis longitudinal sections were prepared, except where otherwise stated. The specimens were cut along the long axis of the elliptical cross section which had formed and was slightly visible after cold work. All micrographs of longitudinal sections shown below are taken with the [001] direction vertical.

\section{Samples for recrystallization in the $\gamma+\gamma^{\prime}$ field}

The recrystallization kinetics in the $\gamma+\gamma^{\prime}$ field were determined using polished [001] oriented cross sections of CMSX-6. Indentations were produced with a prismatic punch of tungsten carbide ${ }^{[1]}$, typically of $8 \mathrm{~mm}$ length and $0.1 \mathrm{~mm}$ depth. After annealing at $1080^{\circ} \mathrm{C}$ (i.e. the first age hardening temperature), the recrystallized area was measured in several sections perpendicular to the indentation edge. 
The influence of surface recrystallization on the mechanical behavior was investigated using solution-annealed cylindrical specimens which were machined to the nominal dimensions (gage diameter: $9 \mathrm{~mm}$ ) before age hardening. The machining parameters were determined in order to generate a rather uniformly recrystallized surface layer of about $0.1 \mathrm{~mm}$ depth over the gage length after the final age hardening heat treatment.

\section{Metallographic techniques}

Polished samples were etched with one of two variants of the so-called Mo-reagent. The first consists of $100 \mathrm{ml} \mathrm{H} \mathrm{H}_{2} \mathrm{O}, 100 \mathrm{ml}$ $\mathrm{HNO}_{3}, 100 \mathrm{ml} \mathrm{HCl}, 6 \mathrm{~g} \mathrm{Mo-acid}$ and is applied for about $5 \mathrm{~s}$. The second one is a mixture of $60 \mathrm{ml}$ of a concentrate $(300 \mathrm{ml}$ $\mathrm{HCl}, 300 \mathrm{ml} \mathrm{H} \mathrm{H}_{2} \mathrm{O}$, and $5 \mathrm{~g} \mathrm{Mo-acid)} \mathrm{and} 50 \mathrm{ml} \mathrm{H}_{2} \mathrm{O}, 30 \mathrm{ml}$ $\mathrm{HNO}_{3}$, and 5 drops of a tensidic agent. This reagent should be prepared shortly before etching and be applied for about $20 \mathrm{~s}$.

\section{Electron microscopy}

The conclusive identification of recrystallized grains as well as the characterization of the orientation distribution of grains in recrystallized areas was performed in a SEM by electron backscattered diffraction (EBSD). Since in most cases the areas of interest lie near the specimen surface, the usual electrolytic polishing could not be applied. Instead, careful mechanical polishing alternating with slight chemical etching produces the required surface quality.

Transmission electron microscopy was employed for characterizing with very high spatial resolution the differences in dislocation structure, orientation, and chemical composition between different regions in the specimens. The near surface position of these regions required electrolytic deposition of a $3 \mathrm{~mm}$ thick nickel layer on the specimen surface, careful mechanical preparation of the disc and final twin jet thinning using a solution of $50 \mathrm{ml}$ perchloric acid in $950 \mathrm{ml}$ ethanol and $100 \mathrm{ml}$ buthanol at $-40^{\circ} \mathrm{C}^{[5,6]}$.

\section{Mechanical testing}

LCF tests were carried out at $980^{\circ} \mathrm{C}$ in air under total strain control with $R_{\varepsilon}=-1$ and ramps with $\dot{\varepsilon}=10^{-3} \mathrm{~s}^{-1}$. The tests were conducted either without hold time or with hold times of $300 \mathrm{~s}$ at $\varepsilon_{\min }$. The testing systems have a capacity of $100 \mathrm{kN}$ and are equipped with low bending moment grips and threezone resistance furnaces. Creep tests were conducted in the same apparatus in air under constant load.

\section{$\underline{\text { Results }}$}

\section{$\gamma^{\prime}$ Solutioning behavior of CMSX-11B}

Recrystallization in the $\gamma$ field depends on the solutioning behavior of the $\gamma^{\prime}$ phase both as secondary precipitates as well as in the $\gamma / \gamma^{\prime}$ eutectic. This was quantified for CMSX-11B in the as-cast condition (Figure 2) which contains about $6 \mathrm{vol} \%$ eutectic. Solutioning is completed within the dendrite cores at about $1205^{\circ} \mathrm{C}$ after $2 \mathrm{~h}$ dwell time whereas the interdendritic regions become single phase above about $1250^{\circ} \mathrm{C}$. Residual $\gamma / \gamma^{\prime}$ eutectic only dissolves at the highest solutioning step of $1260^{\circ} \mathrm{C}$ after $6 \mathrm{~h}$. After SHT the amount of retained eutectic is about $1 \%$ to $2 \%$.

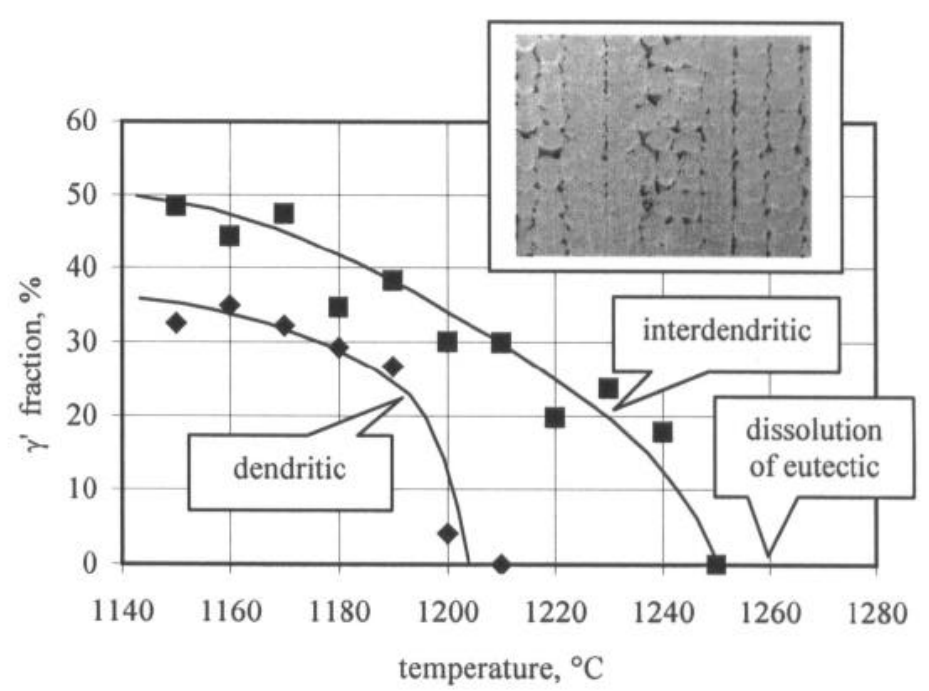

Figure 2: Solutioning behavior of the $\gamma^{\prime}$ phase in CMSX-11B $\left(\right.$ after $\left.{ }^{[7]}\right)$. The micrograph represents the as-cast start condition with about $6 \%$ eutectic.

\section{Recrystallization behavior of CMSX-11B in the $\gamma$ field}

Critical strain $\quad$ After about $1 \%$ compressive strain new grains form in CMSX-11B during solution heat treatment (SHT). After $0.9 \%$ height reduction some grains are located only in the specimen corners and some way along the circumference, Figure 3. After about $2 \%$ strain the specimens fully recrystallize during SHT. Remarkably, all grains break the surface after these degrees of cold work and there are no new grains which have developed in the interior or which are entirely surrounded by other grains. To initiate nucleation in the bulk much higher deformation is needed in this alloy, in excess of about $10 \%$.

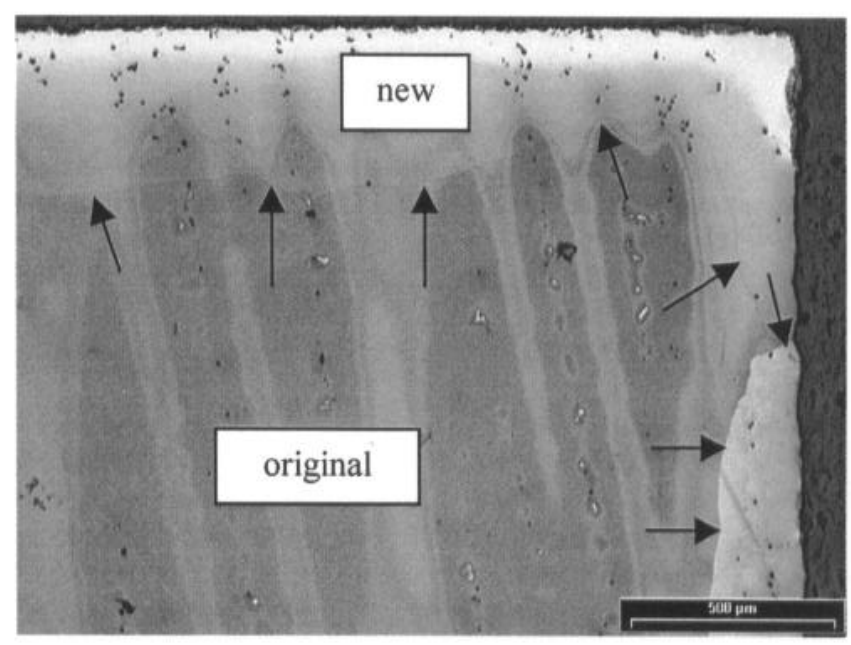

Figure 3: New grains along the surface after $0.9 \%$ height reduction and solution heat treatment (SHT) in CMSX-11B. 
Recrystallization temperature Samples cold worked by $2 \%$ or $3 \%$, which was chosen as the standard degree of deformation, are completely recrystallized after $1 \mathrm{~h}$ at $1249^{\circ} \mathrm{C}$ (the step before last in the solutioning cycle, see Table II). After only $15 \mathrm{~min}$ at this temperature new grains develop along the surface. According to the common definition round $1250^{\circ} \mathrm{C}$ represents the recrystallization temperature for CMSX-11B after $2 \%$ to $3 \%$ strain. All grains have access to the surface which means that they all have nucleated at the surface.

Recovery annealing With $2 \%$ to $3 \%$ cold worked samples a test program was run with the aim to find a recovery procedure that sufficiently reduces the driving force for recrystallization.

Long term annealing at $1220^{\circ} \mathrm{C}$ for up to $100 \mathrm{~h}$, for example, does not prevent complete recrystallization after subsequent full SHT. The same holds true after a $1227^{\circ} \mathrm{C} / 10 \mathrm{~h}$ dwell period. After $10 \mathrm{~h}$ at $1230^{\circ} \mathrm{C}$ the corresponding sample is for the most part recrystallized directly after this annealing (Figure 4).



Figure 4: Grain boundaries (arrows) have overcome interdendritic $\gamma / \gamma^{\prime}$ obstacles in CMSX-11B $\left(2.94 \% ; 1230^{\circ} \mathrm{C} / 10 \mathrm{~h}\right)$. The new grains grow from the surface. (Figure taken from ${ }^{[7]}$ ).

Extremely slow heating with $1 \mathrm{~K} / \mathrm{h}$ from $1220^{\circ} \mathrm{C}$ to $1250^{\circ} \mathrm{C}$ again is not appropriate to avoid complete recrystallization during subsequent SHT. As stated above, in any case there was no indication that new grains have formed in the bulk, in other words they all break the surface.

At all recovery heat treatments some new surface grains develop after rather short exposure. This led to the supposition that these surface grains might be responsible for further growth into the specimen volume. Consequently, one sample was compressed by $2 \%$, annealed at $1220^{\circ} \mathrm{C}$ for $68 \mathrm{~h}$, and then reduced in diameter from $12 \mathrm{~mm}$ to $10 \mathrm{~mm}$ by spark erosion in order to remove surface recrystallization (its depth was checked before). It was subsequently annealed at $1249^{\circ} \mathrm{C}$ for $15 \mathrm{~min}$ to see if new surface grains form again. Indeed, this is the case and complete recrystallization still occurs during full SHT.

To be sure that the observed effects are not influenced by axial compression straining some samples were prepared with $2 \%$ tensile strain. A fully solution heat treated sample again com- pletely recrystallizes with all grains breaking the surface. These findings coincide with those from compression testing.

Annealing in air causes depletion of oxide forming elements in the surface near region which in turn leads to $\gamma^{\prime}$ dissolution. The question arose whether this phenomenon is responsible for the observed surface grain formation. Therefore, some tests were run in a vacuum production furnace. A sample held for $10 \mathrm{~h}$ at $1220^{\circ} \mathrm{C}$, then slowly heated with $1 \mathrm{~K} / \mathrm{h}$ to $1249^{\circ} \mathrm{C}$, followed by the last two steps of SHT $\left(1249^{\circ} \mathrm{C} / 3 \mathrm{~h}+1260^{\circ} \mathrm{C} / 6 \mathrm{~h}\right)$ exhibits only a very thin oxide layer but it fully recrystallizes as the airtested sample does. Also from other comparison tests there is no indication that the results are significantly influenced by the annealing atmosphere.

As long as interdendritic $\gamma^{\prime}$ precipitates are present at a high volume fraction the grain boundaries of new grains nucleated at the surface are pinned along the first "row" of interdendritic $\gamma / \gamma$ ' spaces even after long annealing times, Figure 5 (see also Figure 11 below). Only at higher temperatures when the fraction of interdendritic $\gamma^{\prime}$ is smaller grain boundary motion continues and the deformed microstructure will be consumed and recrystallized, Figure 4.



Figure 5: Grain boundaries (arrows) are pinned at the first "row" of interdendritic $\gamma / \gamma$ ' spaces in CMSX-11B (2.99\%; $1220^{\circ} \mathrm{C} / 97 \mathrm{~h}$ ). Due to oxidation the near surface region is depleted in $\gamma^{\prime}$ and Kirkendall voids also occur. (Figure taken from ${ }^{[7]}$ ).

Cyclic recovery annealing Following some indications in the literature ${ }^{[8,9]}$ cyclic recovery heat treatments were performed on $2 \%$ strained samples. After ten cycles $1000^{\circ} \mathrm{C} / 30 \mathrm{~min} \leftrightarrow 1100^{\circ} \mathrm{C} / 30 \mathrm{~min}$ and final $1204^{\circ} \mathrm{C} / 1 \mathrm{~h}$ again new surface grains develop and the specimens fully recrystallize during SHT as before with static annealing. The most extended test series consisted of in total more than 100 cycles, divided into the following steps:

50 cycles $950{ }^{\circ} \mathrm{C} / 5 \mathrm{~min} \leftrightarrow 1050^{\circ} \mathrm{C} / 5 \mathrm{~min}$

+27 cycles $1050^{\circ} \mathrm{C} / 5 \mathrm{~min} \leftrightarrow 1150^{\circ} \mathrm{C} / 5 \mathrm{~min}$

+29 cycles $1150^{\circ} \mathrm{C} / 5 \mathrm{~min} \leftrightarrow 1200^{\circ} \mathrm{C} / 5 \mathrm{~min}$.

Finally, the SHT was added which again caused full recrystallization. 
All together, no recovery heat treatment without any further manipulation could be found that was able to prevent recrystallization during subsequent SHT.

Coated specimens To move the boundary of deformed material away from the surface and to avoid $\gamma^{\prime}$ dissolution due to oxidation different coating procedures were tried after $2 \%$ cold work. An aluminide layer revealed the most meaningful results. After $1249^{\circ} \mathrm{C} / 1 \mathrm{~h}$ annealing only at some locations a few new grains develop underneath the coating, the rest of the specimen still exhibits the original single crystal, Figure 6. When a specimen is exposed to the full solutioning cycle the coating layer no longer remains continuous, Figure 7. This causes recrystallization only on a small scale and about $3 / 4$ of the original grain still appears.

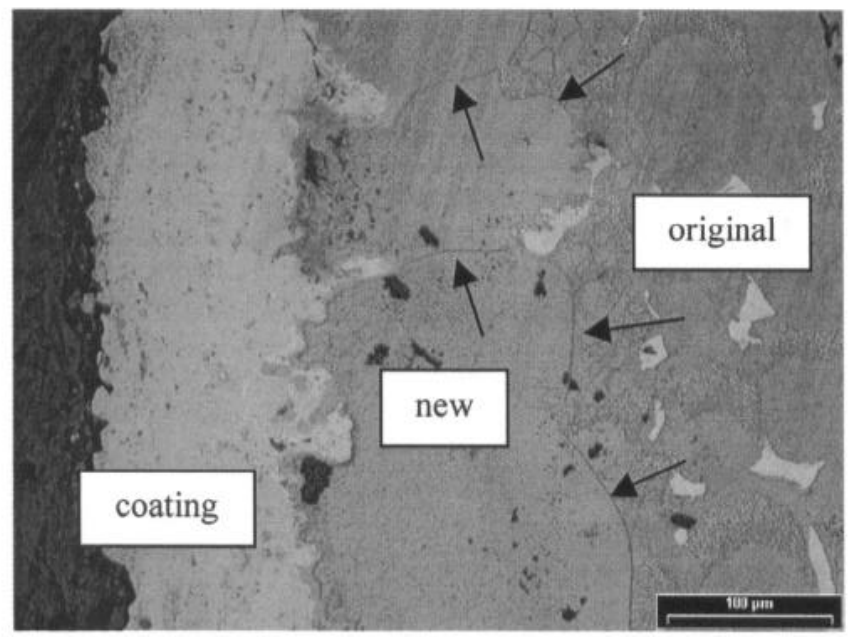

Figure 6: Some new grains underneath an aluminide layer after $2 \%$ cold work, CVD aluminizing, and $1249{ }^{\circ} \mathrm{C} / 1 \mathrm{~h}$ annealing in CMSX-11B (arrows indicate the grain boundaries).

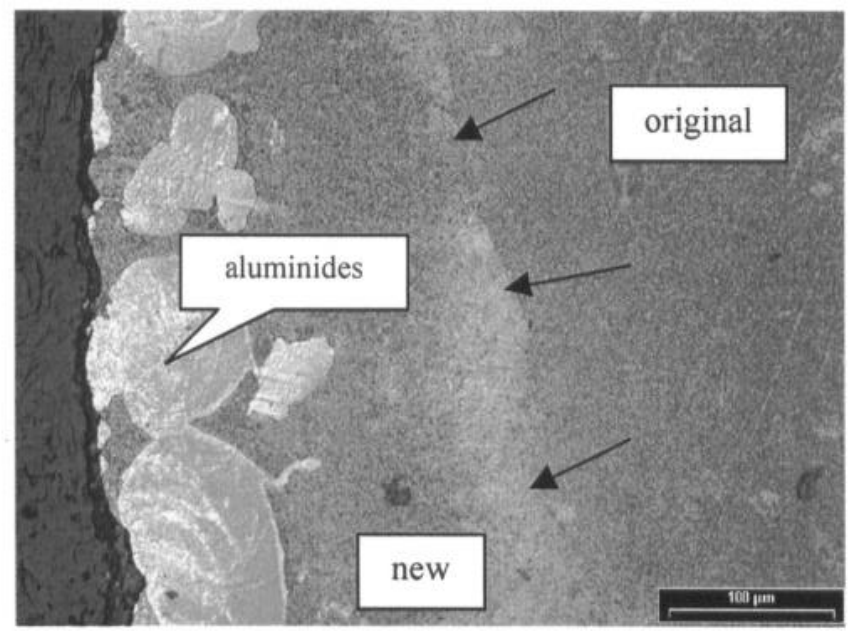

Figure 7: Discontinuous aluminide layer and grain boundary (arrows) after full solutioning cycle in CMSX-11B ( $2 \%$ cold worked and CVD aluminized).

Another $2 \%$ strained and aluminized specimen was annealed for $1249^{\circ} \mathrm{C} / 3 \mathrm{~h}$ and then a jacket was removed by EDM about $1.5 \mathrm{~mm}$ deep and $2 \mathrm{~mm}$ at the faces. Finally the test piece was fully solution treated. The aim of this experiment was to get rid of new grains which certainly have formed during $1249^{\circ} \mathrm{C}$ annealing and to see whether recovery at this temperature eliminates the driving force for recrystallization in the remaining specimen core. After SHT the result was mixed: along the surface some small grains still nucleate but the majority of the volume remains unrecrystallized indicating that indeed bulk recovery dominates in case when surface recrystallization is inhibited.

Influence of carbides To investigate the influence of dispersed carbides on the recrystallization kinetics an experimental derivative of CMSX-11B with $0.08 \mathrm{w} \% \mathrm{C}$ was cast. It was shown that this alloy can be solution treated with the same parameters, i.e. the carbon content does not reduce the melting temperature below $1260^{\circ} \mathrm{C}$ when all prior annealing steps are run. The carbides are concentrated in interdendritic regions and after SHT they appear rather coarse and blocky, sometimes bone-shaped, as primary carbides typically do. They were analyzed as $\mathrm{Ti} / \mathrm{Ta}$ containing MC-type particles, as expected from the alloy composition.

A specimen of this alloy strained $1.88 \%$ and fully solution treated exhibits the same features as the carbide free alloy. The whole volume is recrystallized and all grains have access to the surface. Particular pinning of grain boundaries by the carbides could not be detected.

\section{Recrystallization behavior of PWA 1483 in the $\gamma$ field}

The fully solution treated condition of PWA 1483 looks very similar to that of the carbon version of CMSX-11B, i.e. relatively coarse primary carbides are visible of the $\mathrm{MC}$ type with $\mathrm{Ti}$ and $\mathrm{Ta}$ being the main metallic components.

A sample compressed by $2.11 \%$ completely recrystallizes during SHT, Figure 8. All grains initiate from the surface, too. Heating a $2.12 \%$ cold worked sample to $1249^{\circ} \mathrm{C}$ with the same steps as for CMSX-11B and holding for $1 \mathrm{~h}$ at this temperature also produces full recrystallization. Thus it can be concluded that the behavior is very similar to that of CMSX-11B.

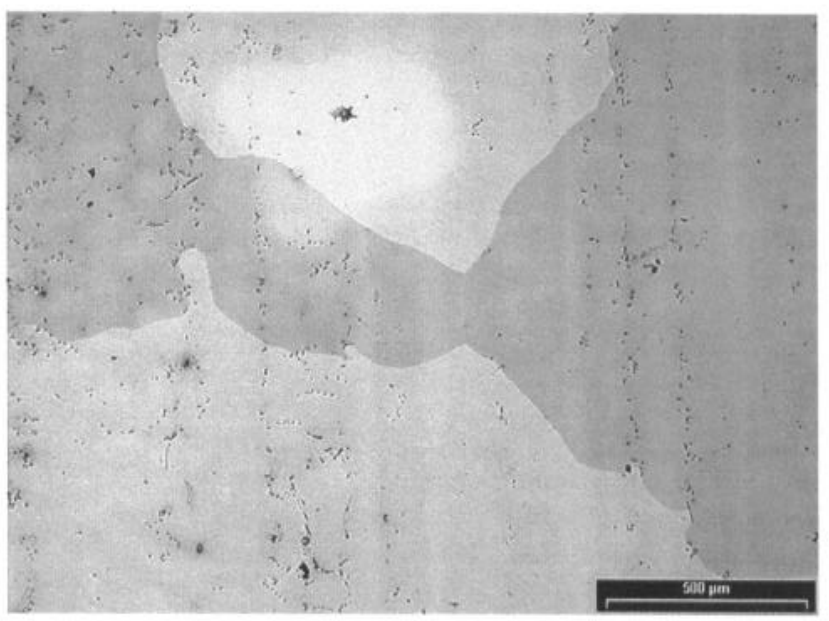

Figure 8: Full recrystallization in PWA 1483 after $2.11 \%$ strain and SHT. The dark particles are MC type carbides. 


\section{Recrystallization behavior of SRR 99 in the $\gamma$ field}

SRR 99 shows pronounced glide bands indicating single slip and, with increasing strain, dual slip on $\{111\}<110>$ slip systems. After $1.83 \%$ strain and full solution heat treatment (see Table II) a band of new grains forms which runs diagonally through the specimen, Figure 9. The rest of the volume remains unrecrystallized. All grains have access to the surface at this degree of deformation. With increasing cold work the width of the recrystallization band increases. A $4.01 \%$ compressed sample, for example, exhibits two crosswise bands with new grains as a consequence of dual slip.

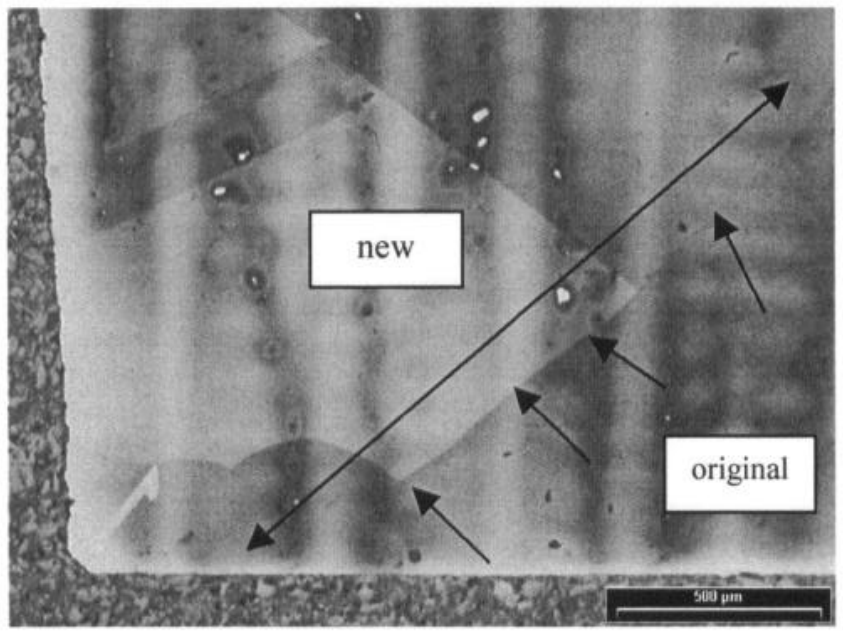

Figure 9: Recrystallization band starting at one corner and running diagonally through the specimen in SRR $99(1.83 \%$ and SHT).

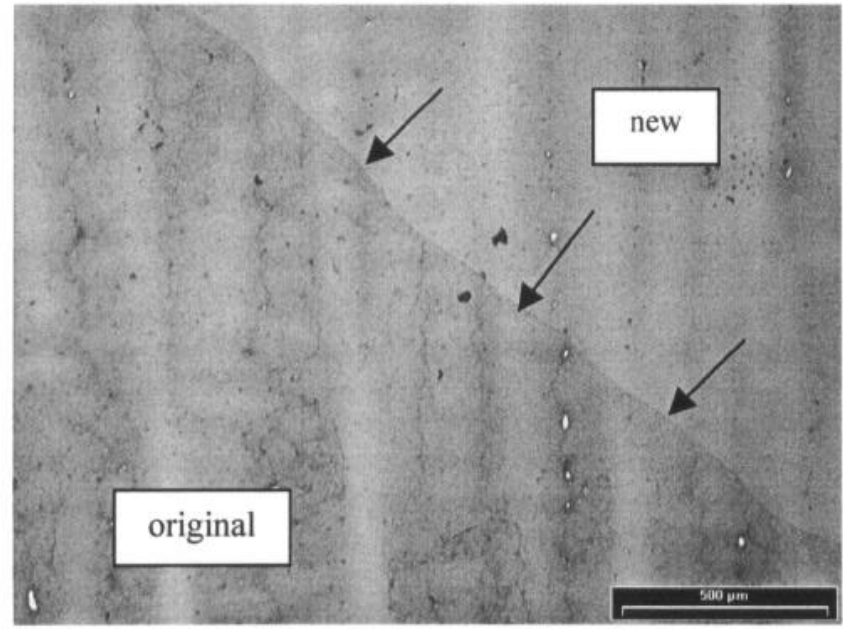

Figure 10: Boundary between a new grain and the original one in SRR 99 after $4.01 \%$ and SHT. Within the original grain a feathery substructure can be detected.

In SRR 99 residues of the original crystal can be clearly distinguished from recrystallized areas by a feathery substructure, Figure 10. At higher resolution in a scanning electron microscope this feature emerges as somewhat coarser $\gamma^{\prime}$ particles which probably reprecipitate on low-angle grain boundaries du- ring cooling from solutioning. Obviously this substructure remains stable also during SHT.

With SRR 99 recovery annealing was tried at $1250^{\circ} \mathrm{C}$ for $10 \mathrm{~h}$. At this temperature the dendrite cores are single phase $\gamma$ but a high amount of $\gamma^{\prime}$ is still present in the interdendritic regions as well as eutectic $\gamma / \gamma^{\prime}$. Where the deformation band runs out of the surface and a dendrite core breaks the surface new grains nucleate after $1250{ }^{\circ} \mathrm{C} / 10 \mathrm{~h}$, Figure 11 (checked after $1.8 \%$ and $3.24 \%$ strain). Always when the SHT is added after $1250^{\circ} \mathrm{C}$ annealing, recrystallization occurs in the way described above for the non-pretreated condition.

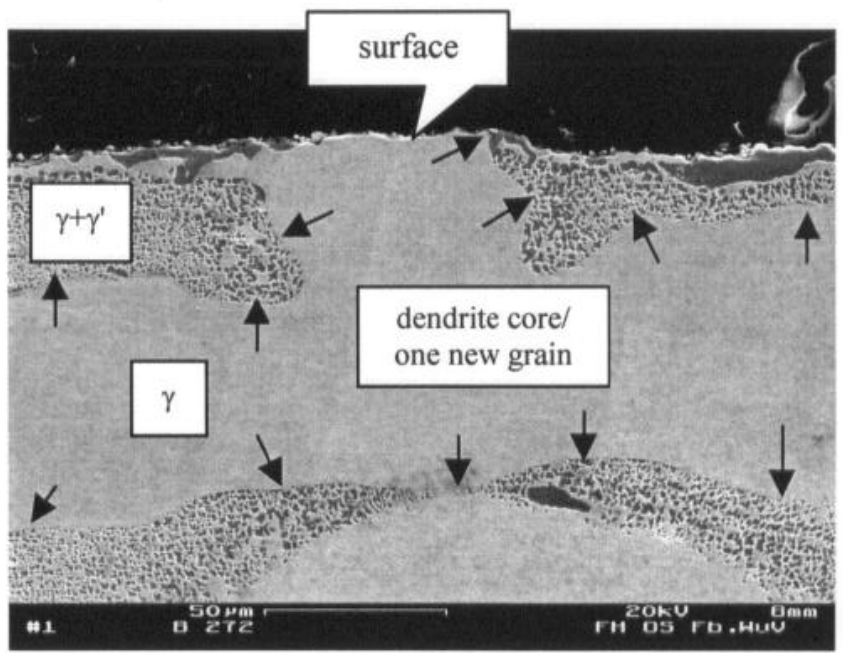

Figure 11: SEM micrograph of grain nucleation at the surface in a single phase dendritic area. The grain boundary (arrows) winds along the interdendritic $\gamma / \gamma^{\prime}$ spaces (SRR 99; $3.24 \%$; $1250^{\circ} \mathrm{C} / 10 \mathrm{~h}$ under vacuum; cross section).

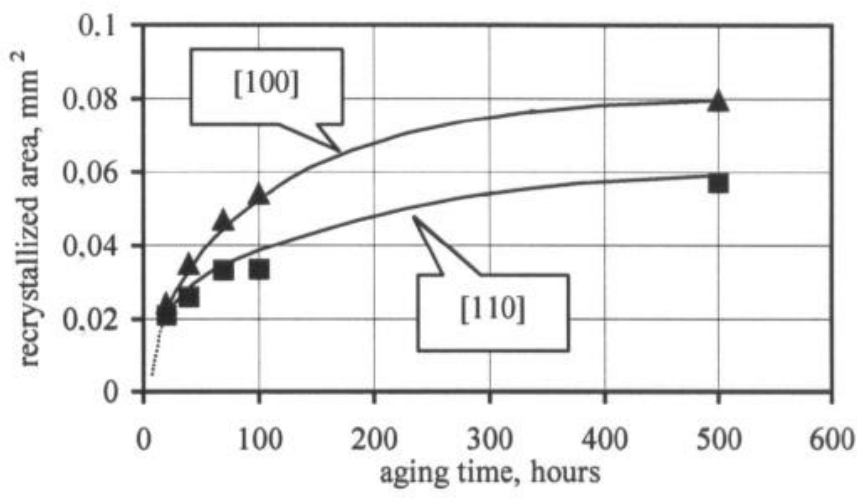

Figure 12: Recrystallized area in CMSX-6 as function of aging time at $1080^{\circ} \mathrm{C}$ for two orientations of the prismatic indenter (evaluated section perpendicular to the indentation edge).

\section{Recrystallization behavior of CMSX -6 in the $\gamma+\gamma^{\prime}$ field}

Kinetic evaluation The time dependence of the recrystallized area in indented CMSX-6 specimens after annealing at $1080^{\circ} \mathrm{C}$ is shown in Figure 12. The anisotropy of this process is clearly reflected by the effect of the edge orientation relative 
to the crystal directions [100] and [110], respectively. Similar results were obtained when determining the machining parameters for LCF specimens.

This experimental approach allows the comparison of different materials with respect to their proneness to recrystallization. The ranking we obtained in this way reflects the practical experience with this phenomenon. It is possible to reduce all the data by using a Johnson-Mehl-Avrami equation ${ }^{[10]}$. The incubation period depends on the applied indentation load, being shorter for higher loads as in Figure 12.

Nucleation In order to nucleate new grains in a $\gamma / \gamma^{\prime}$ microstructure without partially dissolved $\gamma^{\prime}$ the following procedure was chosen. In a previous investigation ${ }^{[11]}$ it was shown that tensile creep deformation produces a gradual change in the morphology of the interdendritic shrinkage pores. Creep fracture is induced by cracks originated at the surface of these pores. Cylindrical specimens of $\mathrm{CMSX}-6$ with the complete heat treatment were creep deformed at $760^{\circ} \mathrm{C}$ and $980^{\circ} \mathrm{C}$, respectively, to a strain of about $15 \%$, generating plenty of cracks around shrinkage pores without contact to the atmosphere. One may assume that the remaining oxygen partial pressure in the pores is very low. After interrupting the creep deformation by unloading, the control mode of the machine was changed and the samples were ruptured at $980^{\circ} \mathrm{C}$ with a high strain rate. After annealing at $980^{\circ} \mathrm{C}$ cellular recrystallization could be observed in many specimens at the crack tips, Figure 13, following the high plastic deformation in these regions.

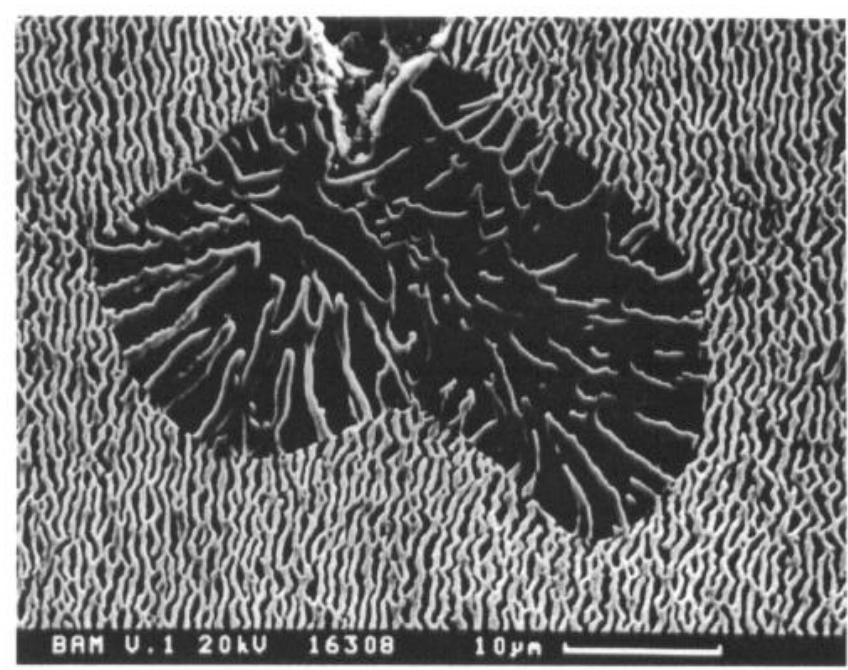

Figure 13: Recrystallized area at a crack tip in a CMSX-6 creep specimen $\left(980^{\circ} \mathrm{C}\right)$ after tensile rupture and annealing at $980^{\circ} \mathrm{C}$ for $96 \mathrm{~h}$.

Microstructural characterization It could be shown that the $\gamma / \gamma^{\prime}$ microstructure in the new grains does not depend on the topological characteristics of the parent grain. In specimens creep tested at $760^{\circ} \mathrm{C}$, where $\gamma^{\prime}$ cuboidal precipitates are embedded in the $\gamma$ phase, as well as in those creep tested at $980^{\circ} \mathrm{C}$, where $\gamma$ platelets are involved by $\gamma^{\prime}$ phase, we observed the same $\gamma / \gamma^{\prime}$ microstructure in the recrystallized region. This microstructure has a much coarser distribution of $\gamma / \gamma^{\prime}$ than the parent grain, Figure 14. Due to the characteristic cells, this process is known as cellular recrystallization. The analysis of the orientation distribution in SEM using the EBSD technique as well as the comparison of TEM diffraction patterns from the parent grain and adjacent recrystallized grains clearly reveal that the cells are grains with high angle boundaries and that there is no unique relationship between the parent and the new grains.



Figure 14: Change in the $\gamma / \gamma^{\prime}$ microstructure of a CMSX-6 specimen due to cellular recrystallization.

The $\gamma / \gamma^{\prime}$ microstructure of a recrystallized volume was registered in eight parallel sections by a serial polishing technique. The distance between neighboring sections lies between $0.5 \mu \mathrm{m}$ and $1.5 \mu \mathrm{m}$. Comparison of the micrographs in different areas shows that the cells consist of a $\gamma^{\prime}$ continuum in which $\gamma$ columns are embedded.

The chemical compositions of both phases in the parent grain and in a recrystallized area were determined by EDX in a TEM specimen, Table III.

Table III Chemical compositions of the $\gamma$ and $\gamma^{\prime}$ phases in the parent grain and in recrystallized areas (RX) of CMSX -6

\begin{tabular}{c|c|c|c|c|c|c|c}
\multirow{2}{*}{ phase } & \multirow{2}{*}{ grain } & \multicolumn{7}{|c}{ mass fraction in \% } \\
\cline { 3 - 8 } & & $\mathrm{Ni}$ & $\mathrm{Cr}$ & $\mathrm{Co}$ & $\mathrm{Mo}$ & $\mathrm{Ti}$ & $\mathrm{Al}$ \\
\hline \multirow{2}{*}{$\gamma$} & parent & 61.3 & 22.4 & 9.0 & 5.8 & .9 & .8 \\
\cline { 2 - 8 } & $\mathrm{RX}$ & 62.8 & 21.7 & 8.4 & 4.9 & 1.2 & 1.0 \\
\hline \multirow{2}{*}{$\gamma^{\prime}$} & parent & 77.3 & 8.3 & 4.7 & 2.9 & 5.6 & 1.4 \\
\cline { 2 - 8 } & $\mathrm{RX}$ & 81.7 & 3.3 & 3.9 & 2.1 & 7.2 & 2.0
\end{tabular}

Influence of recrystallized areas on LCF behavior Figure 15 depicts the influence of a $0.1 \mathrm{~mm}$ deep recrystallized surface layer on the LCF behavior at $980^{\circ} \mathrm{C}$ and a total strain range of $0.7 \%$. The number of cycles to crack initiation, $\mathrm{N}_{\mathrm{A}(5 \%)}$, does not differ significantly between virgin and recrystallized samples in both cycle modes (without and with hold times).

In comparison to specimens with no recrystallization, the density of cracks on the gage length of the recrystallized specimens is higher, especially in the $\langle 110\rangle$ directions (which can be identified by looking at a polished specimen face, i.e. a (001) 
plane). The metallographic analysis of longitudinal sections and fractography confirm this higher crack nucleation rate of recrystallized specimens in comparison with single crystal ones.

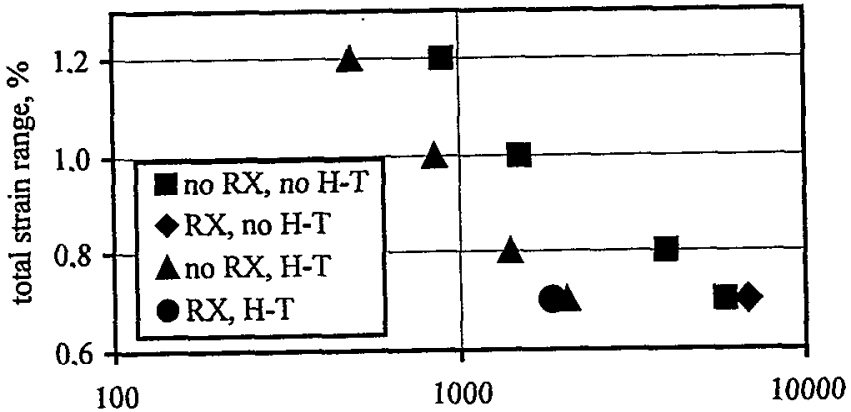

number of cycles to crack initiation, $\mathrm{N}_{A}(5 \%)$

Figure 15: LCF test results of CMSX -6 at $980^{\circ} \mathrm{C}$.

Each symbol represents the average lifetime of two to five specimens. (RX: with cellular surface recrystallization;

$\mathrm{H}-\mathrm{T}$ : hold time of $300 \mathrm{~s}$ at $\varepsilon_{\mathrm{min}}$ ).

\section{Discussion}

\section{Recrystallization in the $\gamma$ field}

The susceptibility of an alloy to recrystallization during solutioning treatment, i.e. when the single-phase $\gamma$ field is approached or reached, is usually tested by hardness indentations or similar non-uniform surface deformation. In the present investigation uniform strain was applied to improve quantification of the relationship between deformation and recrystallization behavior, to improve the comparison between different alloys, and to determine the appearance of recrystallization when the bulk is deformed.

Cold work at room tempcrature is regarded as causing a dislocation structure representative of what develops by short-term high temperature deformation in the $\gamma+\gamma^{\prime}$ phase field, e.g. due to contraction differences between the blade and the shell mold and core. It was estimated that $2 \%$ to $3 \%$ are realistic strain values which can be imposed on the components when the mold and core do not comply sufficiently or crack.

After about $1 \%$ plastic strain the first new grains appear at the surface and less than $2 \%$ causes full recrystallization across the samples. This statement holds true for all alloys investigated for recrystallization in the $\gamma$ phase field. Two conditions need to be satisfied simultaneously to initiate recrystallization after such low degrees of cold work: $i$ ) The $\gamma^{\prime}$ phase must be dissolved in the area of grain nucleation, and ii) a free surface must be available. Dissolution of $\gamma^{\prime}$ alone is not a sufficient prerequisite because then nucleation from internal dendrite cores would also occur as soon as these become single phase. This is definitely not the case.

In the bulk a grain nucleus has to overcome the energy barrier of a grain boundary around the whole grain boundary area whilst along a surface no new interface energy has to be generated. This increases the probability of heterogeneous nucleation at the surface compared to the bulk formation obviously so much that only a small amount of cold work is needed for the former whereas much higher mechanical energy has to be introduced for volume grain nucleation (e.g. more than about $10 \%$ strain in CMSX-11B). For blade assessment these findings mean that if recrystallization has taken place surface grains must in any case be present. If there are none there will be no recrystallization at all. Of course, for hollow blades and vanes the inspection of internal surfaces remains a problem.

With SRR 99 a deviation was observed compared to CMSX$11 \mathrm{~B}$ and PWA 1483 in that slip during cold work is concentrated in prominent glide bands. Consequently, new grains only appear within these bands whereas for the other alloys investigated full recrystallization covers more or less the whole specimen volume. This feature might explain why in industrial practice components cast from SRR 99 may not generally be free of recrystallization but new grains often are small and within the specification.

Experiments with coated samples confirm the hypothesis of energetically favored grain nucleation at surfaces. Despite all difficulties with coating degradation at very high temperatures a clear difference of aluminized samples was observed compared to uncoated ones. If recrystallization from the surface is inhibited by a coating recovery can take place effectively in the bulk when the $\gamma^{\prime}$ precipitates are dissulved completely. Howevcr, this test series only served to improve understanding the nucleation mechanisms and the competition between recovery and recrystallization. In industrial practice it is not feasible to coat the blades to avoid recrystallization during SHT and to strip them afterwards.

All efforts to identify a recovery heat treatment that sufficiently reduces the driving force for primary recrystallization failed. Even unrealistic long annealing times and very low heating rates are not able to annihilate the dislocation structure noticeably below $\gamma^{\prime}$ solvus. TEM examinations of long-term annealed samples confirmed that the dislocation structure is extremely resistant to recovery as long as the dislocations are knitted into the $\gamma / \gamma^{\prime}$ interface. These dislocations supply the mechanical energy that is released by primary recrystallization as soon as the $\gamma^{\prime}$ phase disappcars. Removal of surface grains after nucleation does not prevent complete recrystallization during subsequent SHT which means that indeed the strain energy is stored in the bulk and that the mechanism of primary recrystallization is operating.

For the production of copper crystals with an extremely low dislocation density cyclic recovery annealing can be applied ${ }^{[8]}$. This also forms the background of a patent for monocrystalline superalloys ${ }^{[9]}$. The idea is that dislocation annihilation is enhanced by repeated creation and absorption of vacancies to adjust the equilibrium concentration for the respective temperature. In the present investigation, however, very extended cyclic heat treatments could not avoid subsequent primary recrystallization either.

For most superalloys complete dissolution of $\gamma / \gamma^{\prime}$ eutectic requires significantly higher temperatures and/or longer times compared to dendritic and interdendritic $\gamma^{\prime}$ precipitates (see Figure 2). This temperature "window" is sometimes considered 
to be appropriate to solution treat the alloy completely, except eutectic, on the one hand and to inhibit recrystallization on the other hand because residual eutectic is believed to hinder grain boundary motion. No alloy examined in the present work confirms such a mechanism operating successfully. For example, CMSX-11B exhibits a recrystallization temperature of about $1250^{\circ} \mathrm{C}$ (full recrystallization within $1 \mathrm{~h}$ after $2 \%$ to $3 \%$ plastic strain). At this temperature a fairly high amount of eutectic (more than $5 \%$ ) is still present.

Clearly, grain boundary motion is stopped or at least retarded by interdendritic $\gamma / \gamma^{\prime}$ spaces. A surface grain nucleated where a dendrite core breaks the surface will not grow further when the grain boundary encounters the next $\gamma / \gamma^{\prime}$ area (see Figure 11). Such a small grain might be accoptable in practice. At high enough temperatures and long times, however, these obstacles can be overcome (Figure 4). To utilize this effect would mean to dispense with complete $\gamma^{\prime}$ dissolution at the expense of strength.

Virtually no difference was detected between carbide free and carbide containing alloys. From the present investigations carbides do not seem to be an appropriate measure to inhibit grain boundary motion in the way these particles are present in the $\gamma^{\prime}$ solvus region.

Summarizing, the recrystallization behavior in the $\gamma$ phase field does not differ much among the alloys investigated under the conditions applied. The critical degree of cold work for recrystallization initiation and the mechanisms of heterogeneous grain nucleation at the surface are similar. The extent of primary recrystallization is slightly different, being less for SRR 99 compared to the other alloys examined. This coincides with the experience that, for example, after stamping indentation marks and SHT the recrystallized grains are smaller with SRR 99 compared to other alloys. How much deformation is introduced into the blades during manufacturing is highly geometry-dependant and influenced by core and mold yielding and crushability as well as by the cooling conditions.

\section{Recrystallization in the $\gamma+\gamma^{\prime}$ field}

Cellular recrystallization in superalloys with a high volume fraction of $\gamma^{\prime}$ precipitates occurs by solutioning this phase at the moving grain boundary ${ }^{[12]}$. It is not uncommon to detect this phenomenon in single crystal blades. In comparison to recrystallization in the $\gamma$ field discussed above, a much higher degree of cold work is necessary is this case.

The onset of cellular recrystallization, examined for CMSX -6 , does not require a $\gamma^{\prime}$ free zone in contrast to assumptions in the literature ${ }^{[13]}$. However, it was not possible to identify the mechanism of high angle grain boundary formation in the $\gamma / \gamma^{\prime}$. microstructure and whether a free surface also forms a prerequisite for nucleation as observed in the $\gamma$ field.

Cellular recrystallization is determined by the movement of a grain boundary into the deformed parent material. Due to the crystal disorder in this boundary, it possesses a locally higher solubility and diffusivity than the bulk material ${ }^{[14]}$. The supersaturation leads to decomposition of the single phase immedi- ately behind the moving boundary. This occurs by the formation of $\gamma$ columns perpendicular to the grain boundary in a $\gamma^{\prime}$ continuum. A new grain nucleates and expands as a scction of a sphere, the $\gamma$ columns being homogeneously distributed in radial directions. A section through a recrystallized area shows cells with different shapes of the $\gamma$ rods depending on their angle to the section plane. Since the $\gamma / \gamma^{\prime}$ microstructure in the recrystallized area is much coarser than in the parent phase (Figure 14), the movement of the grain boundary leads to a reduction of the $\gamma / \gamma$ interface energy per unit volume.

The reduction in the free energy associated with cellular recrystallization, $\Delta \mathrm{G}_{\mathrm{RX}}$, may be decomposed into three terms:

$$
\Delta \mathrm{G}_{\mathrm{RX}}=\Delta \mathrm{G}_{\text {mechanical }}+\Delta \mathrm{G}_{\text {interface }}+\Delta \mathrm{G}_{\text {chemical }}
$$

The mechanical term (sign -) reflects the annihilation of dislocations. The second component is related to the microstructural coarsening mentioned above (sign - ) and the creation of highangle grain boundary (sign + ). The third term is assumed to be negligible since the chemical composition of both phases in the recrystallized area is nearly the same as in the parent material.

The crack formation under LCF loading was shown to be facilitated by the presence of a cellularly recrystallized surface laycr. However, the number of cycles to crack initiation,

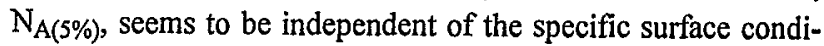
tion of the specimen used in this work, Figure 15. In the present case this is due to the small depth of the recrystallized layer relative to the specimen cross section. Therefore, the common load reduction criterion of $5 \%$ to evaluate $N_{A}$ can only be achieved if the cracks grow into the parent material ${ }^{[15]}$. In the case of thin-walled components the influence can be expected to be more pronounced.

\section{Conclusions}

The present investigations lead to the following conclusions:

(1) Grain formation in the solutioning temperature regime requires only a small critical degree of cold work of about $1 \%$ strain. In a rather wide range of plastic deformation, which in practice most certainly will not be exceeded, grain nucleation mercly starts from the surface for energetic reasons in singlephase $\gamma$ areas. If the deformed surface is subsequently shifted into the interior by an appropriate coating recrystallization can be suppressed. However, this treatment can hardly be utilized in practice.

(2) Grain boundary motion is substantially hindered by interdendritic $\gamma / \gamma^{\prime}$ spaces but not noticeably by carbides or residual eutectic islands. Therefore, if a blade has been deformed to a critical degree it may only be heat treated considerably below the complete solvus of $\gamma^{\prime}$ to avoid larger grains.

(3) No recovery heat treatment could be identified that sufficiently reduces the driving force for recrystallization due to very stable dislocation anchoring around the $\gamma^{\prime}$ precipitates.

(4) Alloys in which deformation is concentrated within narrow glide bands, such as SRR 99 in the present work, exhibit localized recrystallization with possibly acceptable grain size and area fraction.

(5) At lower temperatures in the $\gamma+\gamma^{\prime}$ field cellular recrystallization occurs after much higher amount of cold work. Nuclea- 
tion in this case is not bound to a $\gamma^{\prime}$ depleted zone. The subsequent $\gamma^{\prime}$ microstructure is much coarser than the initial one.

(6) A thin surface layer with cellular recrystallization was found to cause a higher crack density under LCF conditions but the number of cycles to crack initiation according to a load reduction criterion is not influenced under the chosen geometry parameters. For thin-walled components a reduction in LCF strength can be expected.

\section{Acknowledgments}

The following co-workers and students at Osnabrück University of Applied Sciences have contributed to the present work over the past two years: J. Düsterhöft, B. Fischer, H.-G. Kleinheider, K. Mey, T. Michaelis, U. Mussing, and S. Wilkens. The experiments at BAM were performed by A. Riepe and F. Menelao. T. Lübcke of Lufthansa Technik/Hamburg applied the CVD coatings. H. Rooch and W. Gesatzke of BAM, Dr. J. Penkalla of Research Center Jülich, and F. Pyczak of Erlangen University carried out TEM examinations. Prof. $\mathrm{H}$. Mughrabi of Erlangen University gave some valuable advice. Dr. J. Blackford, formerly with Erlangen University, checked the manuscript. The authors gratefully acknowledge all these contributions. The work at Osnabrück University of Applied Sciences and at DPC was promoted by funds by German Ministry of Education, Science, Research, and Technology through Grant 03N2011A and B. The work at BAM was partially supported by Deutsche Forschungsgemeinschaft in the framework of the Priority Program "Microstructure and Mechanical Properties of Metallic High-Temperature Materiais". The responsibility for the content of this publication lies with the authors.

\section{$\underline{\text { References }}$}

1. S.D. Bond, J.W. Martin, "Surface Recrystallization in a Single Crystal Nickel-Based Superalloy", J. Mater. Sci., 19 (1984), 3867-3872.

2. T. Khan, P. Caron, Y.G. Nakagawa, "Mechanical Behavior and Processing of DS and Single Crystal Superalloys", J. Metals, July 1986, 16-19.

3. U. Paul, P.R. Sahm, D. Goldschmidt, "Inhomogeneities in Single-Crystal Components", Mater. Sci. Engg. A173 (1993), 49-54.

4. R.W. Salkeld, T.T. Field, E.A. Ault, "Preparation of Single Crystal Superalloys for Post-Casting Heat Treatment", USPatent 5,413,648 (1995).

5. W. Österle, W. Gesatzke, W. Byrne, "TEM Study of the Effect of Machining on the Microstructure of a Soft Magnetic Ni76Fe17Cu5CrMo2 Alloy", Z. Metallkde., 82 (1991), 902906.

6. W. Österle, P.X. Li, W. Niewelt, "Microstructural Changes Induced by Grinding of Ni-base Superalloy IN $738 \mathrm{LC}$ and their Relationship to Machining Parameters", Z. Metallkde., 85 (1994), 20-27.

7. J. Düsterhöft, "Vermeidung von Rekristallisation gerichtet erstartter Bauteile", Diploma Thesis, Osnabrück University of Applied Sciences, 1998.
8. S. Kitajima, M. Ohta, H. Tonda, "Production of Highly Perfect Copper Crystals with Thermal Cyclic Annealing", J. Crystal Growth, 24/25 (1974), 521-526.

9. W.J. Gostic, "Cyclic Recovery Heat Treatment", US-Patent $5,551,999$ (1984).

10. F. Menelao, "Kinetik und Gefugebildung bei der zellularen Rekristallisation in der einkristallinen Nickelbasis-Superlegierung CMSX-6", Diploma Thesis, Berlin University of Applied Sciences and Economy, 1998.

11. P.D. Portella, C. Herzog, "Gefuigeänderungen und Schädigungsentwicklung der einkristallinen Superlegierung SRR 99 unter Kriechbeanspruchung bei $980^{\circ} \mathrm{C}$, in: Vortragsveranstaltung Rastermikroskopie in der Materialprifung, ed. V. Thien (DVM, Berlin, 1992), 51-60.

12. A. Porter, B. Ralph, "The Recrystallization of Nickel-Base Superalloys", J. Mater. Sci., 16 (1981), 707-713.

13. B. Ralph, C.Y. Barlow, B.A. Cooke, A.J. Porter, "The Recrystallization of High Performance Alloys", in: Proc. $1^{\text {st }}$ Risø Int. Symp. on Recrystallization, ed. N. Hansen et al. (Roskilde: Risø Nat. Lab., 1980), 229-242.

14. K. Smidoda, W. Gottschalk, H. Gleiter, "Diffusion in Migrating Interfaces", Acta Met., 26 (1978), 1833-1836.

15. P.D. Portella, W. Österle, "Influence of Cellular Recrystallization on the Fatigue Behaviour of Single Crystal Ni-Based Superalloys", in: Microstructure and Mechanical Properties of Metallic High-Temperature Materials, ed. H. Mughrabi et al. (Weinheim: Wiley-VCH, 1999), 441-453. 